\title{
Modelling infectious viral diseases in swine populations: a state of the art
}

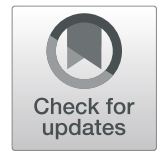

\author{
M. Andraud ${ }^{*}$ (D) and N. Rose
}

\begin{abstract}
Mathematical modelling is nowadays a pivotal tool for infectious diseases studies, completing regular biological investigations. The rapid growth of computer technology allowed for development of computational tools to address biological issues that could not be unravelled in the past. The global understanding of viral disease dynamics requires to account for all interactions at all levels, from within-host to between-herd, to have all the keys for development of control measures. A literature review was performed to disentangle modelling frameworks according to their major objectives and methodologies. One hundred and seventeen articles published between 1994 and 2020 were found to meet our inclusion criteria, which were defined to target papers representative of studies dealing with models of viral infection dynamics in pigs. A first descriptive analysis, using bibliometric indexes, permitted to identify keywords strongly related to the study scopes. Modelling studies were focused on particular infectious agents, with a shared objective: to better understand the viral dynamics for appropriate control measure adaptation. In a second step, selected papers were analysed to disentangle the modelling structures according to the objectives of the studies. The system representation was highly dependent on the nature of the pathogens. Enzootic viruses, such as swine influenza or porcine reproductive and respiratory syndrome, were generally investigated at the herd scale to analyse the impact of husbandry practices and prophylactic measures on infection dynamics. Epizootic agents (classical swine fever, foot-and-mouth disease or African swine fever viruses) were mostly studied using spatio-temporal simulation tools, to investigate the efficiency of surveillance and control protocols, which are predetermined for regulated diseases. A huge effort was made on model parameterization through the development of specific studies and methodologies insuring the robustness of parameter values to feed simulation tools.

Integrative modelling frameworks, from within-host to spatio-temporal models, is clearly on the way. This would allow to capture the complexity of individual biological variabilities and to assess their consequences on the whole system at the population level. This would offer the opportunity to test and evaluate in silico the efficiency of possible control measures targeting specific epidemiological units, from hosts to herds, either individually or through their contact networks. Such decision support tools represent a strength for stakeholders to help mitigating infectious diseases dynamics and limiting economic consequences.
\end{abstract}

\footnotetext{
* Correspondence: mathieu.andraud@anses.fr

Anses, French Agency for Food, Environmental and Occupational Health \& Safety, Ploufragan-Plouzané-Niort Laboratory, Epidemiology, Health and Welfare research unit, F22440 Ploufragan, France
}

(c) The Author(s). 2020 Open Access This article is licensed under a Creative Commons Attribution 4.0 International License, which permits use, sharing, adaptation, distribution and reproduction in any medium or format, as long as you give appropriate credit to the original author(s) and the source, provide a link to the Creative Commons licence, and indicate if changes were made. The images or other third party material in this article are included in the article's Creative Commons licence, unless indicated otherwise in a credit line to the material. If material is not included in the article's Creative Commons licence and your intended use is not permitted by statutory regulation or exceeds the permitted use, you will need to obtain permission directly from the copyright holder. To view a copy of this licence, visit http://creativecommons.org/licenses/by/4.0/. The Creative Commons Public Domain Dedication waiver (http://creativecommons.org/publicdomain/zero/1.0/) applies to the data made available in this article, unless otherwise stated in a credit line to the data. 


\section{Introduction}

Infectious diseases represent a global threat to humans, livestock and wildlife animals and plants with potential cross-species transmission [1, 2]. Mitigating infection is therefore a one-health problematic, which needs to be addressed using all materials in hands, both in terms of research and resources. When referring to such problems, one commonly thinks about biological analysis, i.e. virological and immunological diagnostics, which are essential for the understanding of host-pathogen interactions [3-5]. Epidemiology aims at describing and analysing health disorders at the population level [6-8]. A specific branch of epidemiology often referred to synthetic epidemiology is dedicated to the identification of factors favouring or impairing infections of hosts, and how modifying these factors would alter the transmission process of the infectious agents. The last decades have seen the emergence of mathematical tools developed for the treatment of data related to infectious diseases dynamics [9-11]. Altogether, this toolset offers an analytic power to disentangle the interplay between virological, immunological and epidemiological processes through an integrative approach from within-host to population scales [12].

Swine production represents one third of meat consumption throughout the world, making pig industry one of the most important agricultural sector [13]. In this context, infectious diseases affecting pigs may therefore have dramatic consequences on the food chain supply. The recent outbreak of African swine fever (ASF) in China, the first pork meat consumer country, clearly illustrates the direct and indirect economic impact of the disease [14]. Indeed, a loss of more than 1 Million animals due to 165 declared ASF outbreaks was recorded throughout the country [15], inducing a global shift in world pork market with huge economic consequences. Apart from ASF, swine industry is also affected by several enzootic viral diseases, most of which impair the productivity of herds, being therefore of huge economic importance (e.g. Porcine Reproductive and Respiratory syndrome (PRRS), Porcine Circovirus of type 2 (PCV-2)), and some of which being of public-health importance due to their zoonotic nature, such as swine influenza virus (SIV) and hepatitis E virus (HEV). In both cases, in-depth understanding of infectious diseases dynamics is needed to adopt appropriate solutions to mitigate the infectious pressure among the host population.

The present paper will review the use of mathematical dynamic modelling addressing viral infectious diseases in pigs. The aim was to assess how the field is represented in the literature and to characterize which kind of modelling choices and approaches are made according to the objectives.

\section{Methods}

A literature search on PubMed and Scopus databases was performed on March 28, 2020, including articles with the following terms as keywords, title or abstract terms: (pig OR swine) AND (virus OR "viral infection" OR "viral disease") AND (simulation OR mathematical OR stochastic OR estimation OR inference) AND (model OR modeling OR modelling). In the present review, being dedicated to viral infectious diseases modelling, we decided to swipe relatively large, to include studies presenting mechanistic formulation of viral spread at different scales. This led to the preselection of 907 records (Pubmed: 458; Scopus: 449) from which 273 were duplicates.

The titles and abstracts of 634 articles published between 1994 and 2020 were screened to select articles presenting dynamic models of viral diseases in domestic pig production system. All mechanistic modelling approaches representing the transmission of pathogens in swine populations were first selected. Therefore, papers on virological or immunological aspects were excluded (169 papers), as well as statistical studies for risk factors analysis, quantitative risk analysis (98 papers) or models aiming at economic evaluation of interventions in infected premises (21 papers). Finally, 147 studies focusing on bacteria or alternative host species were discarded as well as 82 studies not considering mathematical approaches (e.g. experimental infection, in vitro models or field study analysis). Prisma flow diagram is displayed in Fig. 1. A bibliographic analysis was first performed to have a global overview of our selection using bibliometric package from $\mathrm{R}$ software [16]. This analysis allowed for disentangling the studies in regards with the modelling frameworks and objectives.

With these considerations, selected records were split into four different categories owing to the objectives of the studies:

(i) Understanding host-pathogen interaction (6 studies),

(ii) Inferring epidemiological parameters (32 studies),

(iii) Assessing infection dynamics and mitigation measures at herd scale (29 studies),

(iv) Assessing surveillance and control measures at large geographical scale (50 studies).

For each of these themes, modelling strategies and objectives will be generally discussed with some concrete references derived from the literature review. 


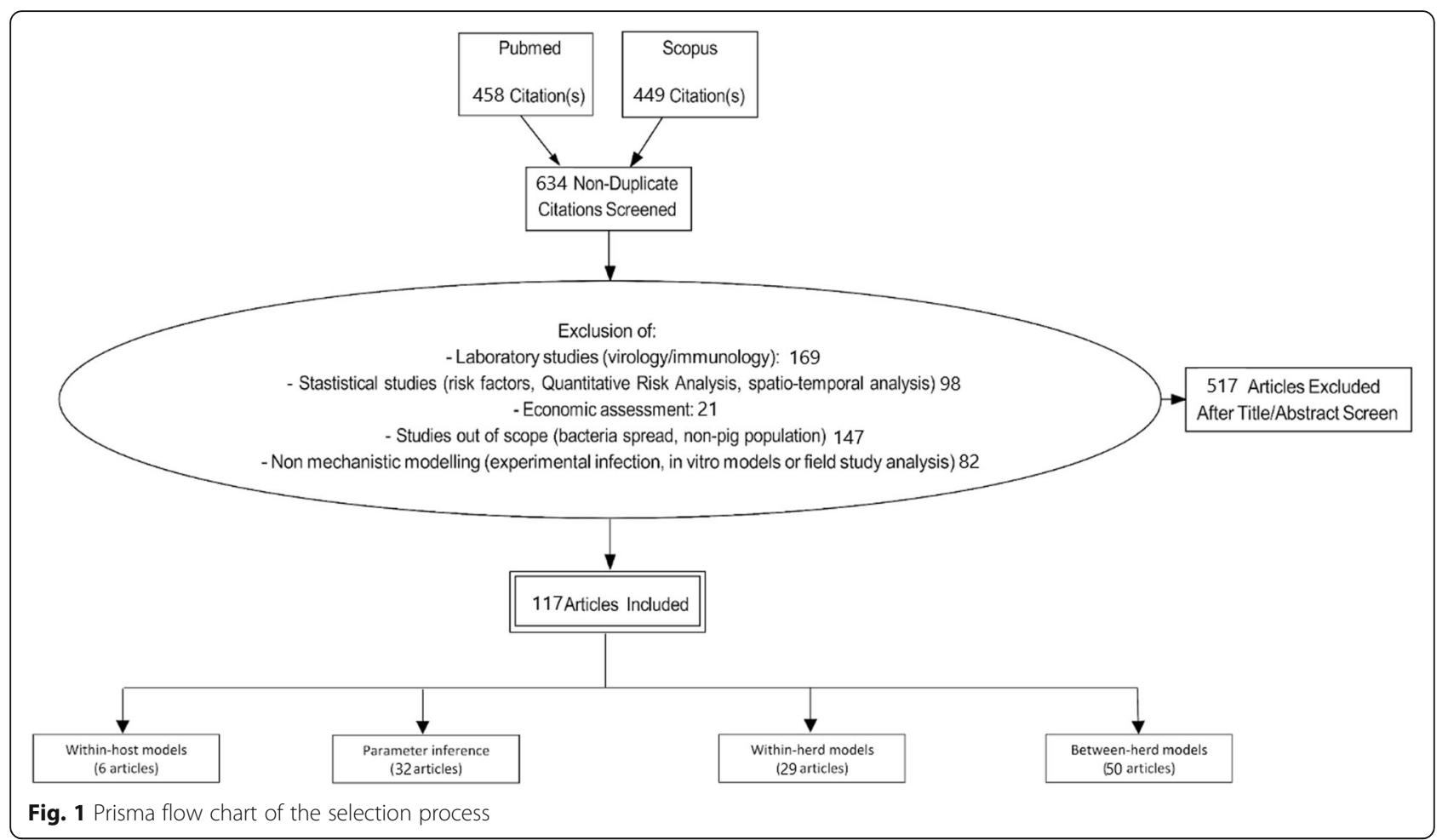

\section{Results}

\section{Descriptive analysis}

Based on the selection process, 117 records finally met the inclusion criteria (Supplementary Material 1). The earliest records were published in 1994, and these modelling studies were dedicated to pseudorabies virus, responsible of Aujeszky's disease, in the Netherlands and United-States, respectively $[17,18]$. As shown in Fig. 2, reflecting the evolution of the number of studies per year, the rise of modelling studies on viral diseases in pigs occurred in the mid-2000's, with a prominence of open access publications in the last 4 years. Veterinary journals have been mainly targeted (representing about $65 \%$ of publications) but five journals with broader scopes are in the 10 major journal list (Supplementary Material 2).

This specific research field was mostly treated by European teams, especially Dutch, French and UK research centers (with 25, 17 and 12 first-author publications, respectively), along with US teams accounting for 17 publications (Fig. 3).

The frequency of keyword use over time is represented in Fig. 4. Queried keywords were systematically retrieved in the selected records, several

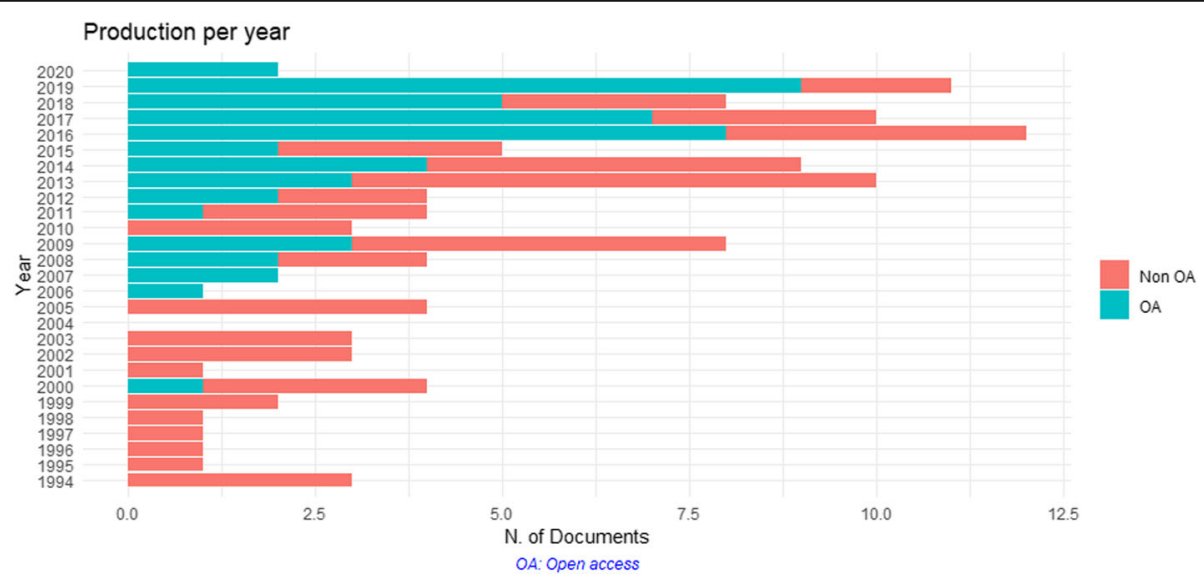

Fig. 2 Evolution of scientific production in pig disease modelling per year 


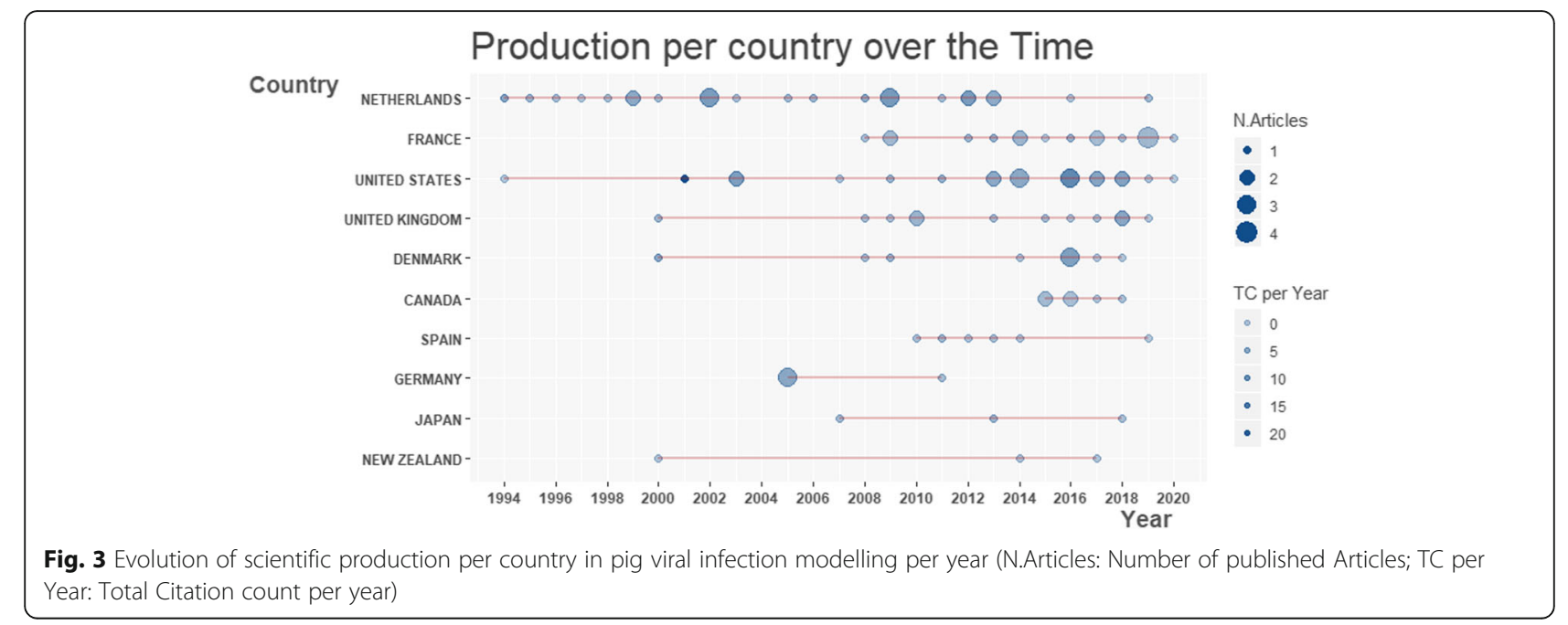

complementary ones were also identified. Apart from search terms, viral infections of major economic importance were on the top of authors'keywords along with terms related to modelling objectives. The major viral diseases affecting pigs being main concerns for the swine industry are often used as primary keywords. Classical swine fever (CSF) was on the top of keywords with a total of 21 occurrences from 1999 $[19,20]$ to 2014 [21]. PRRS, ASF, FMD, SIV and HEV figured out in the 15 most used keywords, reflecting the variety of pathogens targeting pigs. CSF, FMD or PRRS have been involved in modelling studies continuously since 1994, while SIV and ASF have been only investigated recently, after the 2009 swine influenza pandemic and the emergence and spread of ASF in Europe respectively. The applied nature of modelling studies in swine populations is also highlighted by specific keywords corresponding to the main objectives of the studies, control of pathogen being the common purpose of all studies (Fig. 4).
However, control strategies may take different forms depending on the disease under consideration. Indeed, two groups of infectious agents can be established corresponding to epizootic and enzootic diseases and raising different issues to modellers. Indeed, enzootic diseases, such as PRRS or SIV, which cause huge economic losses for swine producers, raise the question of their persistence on farms, despite vaccination programs. Here, the question of within-farm infection dynamics is of primary importance along with the evaluation of alternative, or complementary mitigation strategies, such as modifications of husbandry practices. In contrast, the control of epizootic diseases such as CSF, ASF or FMD, requires evaluating the between-herd spread, as well as surveillance strategies to evaluate the capacity and the cost-effectiveness of the different control measures. Modelling control of infectious diseases requires an in depth understanding of the transmission process at all scales, through the specification of mechanistic relationships, the

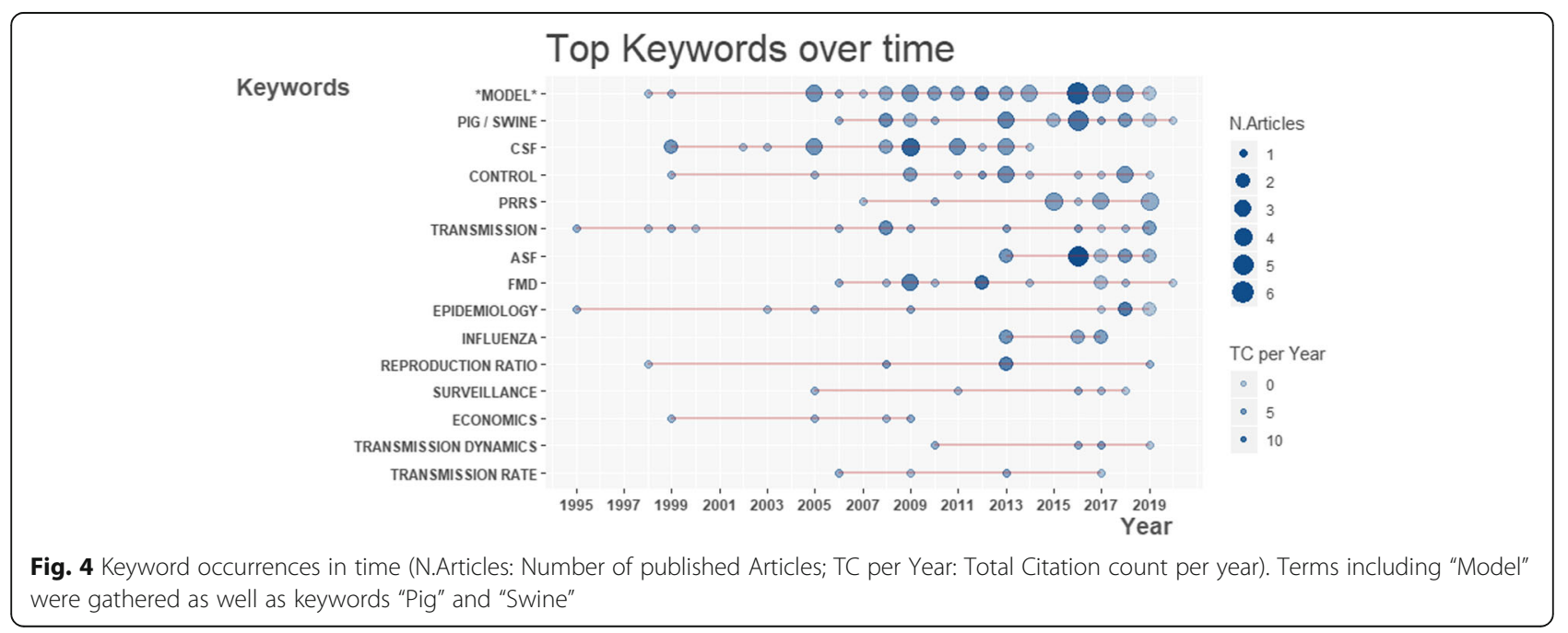


identification and the estimation of key parameters, as the basic reproduction number, to feed simulation tools.

\section{Comprehensive review of modelling approaches and objectives \\ Understanding host-pathogen interaction}

The analysis of infection characteristics at the host-scale may provide important insights on the infection dynamics at population scale. Indeed, the response to infection may be highly heterogeneous between hosts impacting the disease dynamics at population scale. The simplest models considered the interaction at the cellular scale with the infection of target cells and viral replication and release, and has been used to evaluate the impact of the FMD infectious dose on within-host viremia kinetics [22]. The other five studies were dedicated to within-host kinetics of PRRS virus infection, which induces an immuno-modulation, potentially favouring co-infections, and is therefore of particular importance having regard to host-pathogen interactions. Doeschl-Wilson and Galina-Pantoja [23] presented models of increasing complexity to account specifically for host immunity. This work allowed building up an integrative approach to represent the interaction between viral replication and the immune response, to further understand the persistence of viremia and between-host variability of PRRS [24-26].

\section{Inferring transmission parameters (blue highlight in Supp. Mat. 1)}

Mathematical formalisation of biological systems relies on the identification of state variables and mechanisms governing between-state transitions. Parameter values play an essential role to feed simulation tools. One may distinguish two frameworks for parameter estimation. First, the inference from experimental data: experimental studies offer the opportunity to analyse in a fully controlled environments specific characteristics of viral transmission. Different strategies exist for parameters estimation, all relying on relevant data gathered on the field or experimentally and on preestablished model structures [27]. Such approach requires a clear identification of knowledge gaps and the development of specific experimental designs to obtain accurate data to fill these gaps [28]. To estimate epidemiological parameters, data usually consist in the follow-up of infection sequence of naïve pigs in contact with inoculated ones [29-31]. Twenty-three articles from our selection focused on the analysis of experimental data. Such analyses were initiated by De Jong, Bouma and Kimman, with a particular focus on pseudorabies virus, the transmission of pathogens being quantified in different contexts depending on the contact structure between individuals or the immune status of the host [17, 32, 33]. The methodology was then adapted to different viruses such as PCV-2, FMD or more recently ASF, for which direct contact with penmates and indirect contact between animals housed in neighbouring pens are the main transmission routes $[28,34,35]$. The inference framework was also extended to account for alternative transmission routes, using specific data related to the viral load present in the air for SIV or in the environment (HEV) [29, 36]. For all these approaches on parameter inference in an experimental context, the underlying model is a stochastic Susceptible-Infectious-Recovered model where the infection pressure - or force of infection (FoI) - exerted on naive animals is proportional to the prevalence of infected pigs in the population. The proportionality factor, denoted $\beta$, represents the transmission rate, i.e. the average number of new cases produced by one infectious animal per time unit [9]. This parameter, along with the duration of the infectious period, are the key components for the evaluation of the basic reproduction number $\left(R_{0}\right)$. Parameter estimations are usually based on likelihood approaches: the parameter space is scanned to find the optimal values that maximize the probability of observing the whole dataset given the model structure. Deterministic approaches, using minimization algorithms, were first used, but Bayesian frameworks are more and more present in the literature to unravel unobserved processes [37-39].

These Bayesian approaches are also used for parameter estimation from observational data [37, 40]. The rise of approximate Bayesian computation methods provides new toolsets for parameter inference [41]. This method consists in the definition of a metric to measure the adequacy of the model outcomes with observed data. Simulations are then performed with parameter set drawn from prior distributions. The parameter set are accepted and stored if the model outcomes are close enough to the actual data, based on the predefined metric. The selected parameter values define the posterior distribution for the parameter set. Guinat et al. [42] used this method to estimate epidemiological parameters from ASF mortality data in nine pig farms in Russian Federation. With $R_{0}$ ranging from 4.4 to 17.3 , this study highlighted farm specific spreading patterns, which were likely related to husbandry and biosecurity farm specific measures.

Parameters are essential components for model development and analysis. Their roles and values may modify in a critical way the behaviour of the outcome variables. Insuring the robustness of parameter values allows for stronger analysis of external factors influencing the infection dynamics at population scale.

\section{Assessing infection dynamics and mitigation measures at herd scale (yellow highlight in Supp. Mat. 1)}

Twenty-nine records were dedicated to dynamic models of viral infection transmission at the herd level with a similar goal: representing the infectious process in regards with epidemiological knowledge to test strategies 
for mitigating the viral spread [43-45]. These models particularly focused on enzootic pathogens, i.e. PCV2, SIV, PRRS gathering 17 articles. Population models capturing the demographic processes in swine herds are therefore coupled with specific epidemiological models representing the infection history for the pathogen under study. For pigs reared in groups of relatively small sizes, stochastic frameworks have been privileged [43, 46-49], although deterministic approaches based on ordinary differential equations were also developed. The latter were either theoretical models with in depth mathematical analysis, providing insight into the model behaviour according to epidemiological assumptions or parameter values [50-53], or applied models with an accurate representation of the farm systems [54-56]. For illustrative purpose, the issue of on-farm persistence of SIV represent a quarter of the selected articles. The set of companion papers by Reynolds et al. [56] and Etbaigha et al. [54] dealt with the spread of influenza virus in breeding and farrow-to-finish pig herds using deterministic modelling frameworks. The herd structure was described in details accounting for animal movements between different barns. The authors showed how easily the virus became endemic once introduced in a free herd. Indeed the frequency of piglet birth induced a regular inflow of susceptible individuals allowing for viral persistence. Only homologous vaccination - assuming total vaccineinduced protection - strategy was able to mitigate the infection. However, such level of protection is entirely theoretical and several factors may impair the development of the immune response. (e.g. maternally derived antibodies (MDA)). Stochastic models were also developed to address the influenza issue. Pitzer et al. [57] represented three types of herds, i.e. farrow-to-finish, wean-to-finish, and finisher farms. The herds were represented with barns housing pigs of similar physiological statuses and assuming specific contact rates between these barns to assess the within-herd persistence of SIV according to herd size. A critical herd size (CHS) of 3000 individuals was evidenced for SIV persistence with assumed $R_{0}$ values between 1.5 and 2.5. However, experimental studies revealed much more effective transmission with $R_{0}$ values ranging from 10.4 to 14.8 which would lower the estimated CHS. Cador et al. $[58,59]$ identified MDA as playing a major role in the persistence of SIV on farm. A stochastic model was developed considering batches as main epidemiological units, accounting specifically for the relationship between the sows and their litters through delivery of maternally derived immunity. The partial protection conferred by this passively acquired immunity was found to slow down the infectious process in young piglets but extended the infectious process at the batch level, favouring between batch transmission. This modelling framework was further extended to represent the spread of two antigenically distant SIV subtypes. Throughout the simulation process, concomitant infections by the two subtypes represented $16 \%$ of infection events, potentially inducing a risk of reassortment. The evaluation of different control measures showed that vaccination poorly managed to reduce SIV transmission, confirming previous results from other studies.

The study of some pathogens may require considering thinner epidemiological scale with the use of agent-based models. Such approach allows for the inclusion of individual variability, which may play a role in the infectious process at the population level. This was especially the case for HEV due to the evidence of transmission enhancement in pigs co-infected with immune-modulating viruses (IMV; e.g. PRRS). Salines et al. [60] analyzed the spread of HEV in farrow-to-finish pig farms through the development of an agent-based framework describing the co-circulation of HEV along with an immune-modulating virus. Such approach allowed for the analysis of modifications of husbandry practices acting on individual animals, but having a more general impact on the course of infection (e.g. cross-fostering, pig mingling in pens) [43]. A higher HEV persistence probability was evidenced in the presence of IMV, as well as in herds managed with intensive batch-rearing systems ( 20 batches) for which the birth of susceptible individuals is more frequent. The herd structure and husbandry practices, such as cross-fostering and piglet mingling, were also highlighted as important factors for HEV management.

Within-herd models are also developed in view of surveillance evaluation purposes, especially for notifiable diseases such as CSF or ASF. Backer et al. [47] evaluated the effectiveness of mortality-based detection measures of CSF applied in Netherlands in 2010 and found that it was strongly dependent on the physiological states of the animals. The high natural mortality rate (apart from CSF) in piglets impaired the detection process, as was the case in breeding animals due to low CSF-associated mortality. The protocol was nevertheless effective in fattening units where CSF-mortality could be disentangled from natural death, shortening the detection delay from 2 days. Costard et al. [61] integrated data on farmer's behaviours to a within-herd ASF transmission model to assess their risk on virus spread due to release of infected animals. This study highlighted the importance of backyard and smallsize herds and suggested those as potential target for surveillance purpose since they may deliver infected animals through their trade contact network.

\section{Assessing surveillance and control measures at large geographical scale (Orange highlight in Supp. Mat. 1)}

Based on the selection process, between-herd infection spread was assessed in 50 research studies, along with 
evaluation of surveillance and control measures. The earliest model focused on pseudorabies transmission between herds, showing the importance of Aujeszky disease in the 90's and the need for modelling studies to evaluate the feasibility and efficacy of strategies for its eradication in several European countries [18]. Buijtels et al. [62] built a model considering the herd as the epidemiological unit and used a transition matrix including 24 heath states to analyse the impact of vaccination strategies. Van Nes et al. [63] developed a model considering both within- and between-herds transmission, in order to analyse the impact of control measures at farmlevel and the infectious dynamics at larger scale.

In early 2000's, a particular focus was made on footand-mouth disease due to a large outbreak in the UK. Fifteen studies focused on FMD considered multispecies models including cattle, sheep and pig herds. As such, pigs were considered in these models as potential hosts for FMD infection, but were not the target of the studies. Although pigs played a minor role in 2001 UK epidemics $[64,65]$, the role of swine holding was expected to be much higher in Denmark or Netherlands, clearly extending the outbreak persistence $[65,66]$. These studies first aimed at unravelling the roles of the different transmission routes on between-farm transmission, such as animal movements or local spread through airborne route [67-69]. Control measures, consisting in ringvaccination or ring-culling, could then be implemented in the models to evaluate their efficiency on the final size of the epidemics and the outbreak duration. Large radius ring-vaccination ( $>10 \mathrm{~km}$ round from infected herds) was found to be relatively efficient to limit the outbreak size compared with ring-culling strategies [69-71].

About 15\% of the between-herd transmission models focused on CSF (18 papers), a regulated disease, with similar objectives as the ones applied to FMD. Modelling frameworks could be shared for the two problematics $[68,72]$. However, conversely to FMD, CSF is specific to swine, and multi-scale modelling was therefore more frequent in this case, representing explicitly the on-farm dynamics of infection [21, 73, 74]. Backer et al. [75] developed such a framework combining the within-herd transmission, considering mechanistic transmission between penmates and neighbouring pens, and the between-herd transmission, using distance kernel transmission from neighbouring herds. This framework allowed the evaluation of control strategies consisting in ring-culling or ring-vaccination from 1 to $5 \mathrm{~km}$ radius. Two $\mathrm{km}$-ring vaccination was evaluated as efficient as ring-culling. However, vaccination would induce a higher number of undetected epidemics, and a specific end-screening protocol, targeting vaccinated herds, would be necessary. The authors further studied the impact of additional administration of antivirals in sows
[76]. This treatment was found to improve significantly the control measures previously tested, showing the importance of the within-herd process representation, including breeding and growing pigs, to go deeper in the representation of detailed control strategies.

Generic modelling frameworks were also developed in view of homogenization and reproducibility of the methodology used for between-herd models. Four major frameworks were used to model pig viral infections at large geographic scales, namely: InterSpread [ISP] [7779], North America Animal Diseases Simulation Model [NAADSM] [80-83], Danish Technical University Davis Animal Disease Model [DTU-DADS] [84, 85], and Between-Farm-Animal Spatial Transmission [Be-FAST] $[21,86,87]$. All models are fed with herd characteristics (farm types, sizes and locations), and account for direct, indirect, airborne and environmental transmission routes. Boklund et al. used ISP framework to evaluated nine control strategies towards CSF in Denmark based on their effectiveness in reducing disease burden and infection durations. The NAADSM framework was used to evaluate the consequences of the introduction of a highly virulent strain of Porcine Epidemic Diarrhoea (PED) virus in a densely populated area in France [82]. The high responsiveness when the first detection occurs, with movement restriction and stamping out of infected herds within 10 days, appeared essential for limiting the infection spread. This framework was also used to assess the spread conditions of PRRS virus in Canada, highlighting the role of indirect contacts through truck sharing, and thus the importance of strict biosecurity measures for mitigating the transmission process [83]. Be-FAST and DTU-DADS model account explicitly for within-herd spread modules, assuming homogeneous mixing, to assess the overall infectious pressure exerted on susceptible herds, through local transmission (e.g. airborne) or trade exchanges. They also integrate an economic module to evaluate the cost-effectiveness of intervention strategies. Recently Halasa et al. published a set of papers describing the consequences of introduction of ASF in Denmark and assessed the efficacy of control measures using the DTU-DADS modelling framework $[85,88,89]$. The Be-FAST framework was used to study the transmission patterns of ASF in Sardinia, the only European region where the virus became endemic after its introduction in 1978 [87]. The role of unregistered domestic pigs and wild boars was clearly highlighted as a key component for ASF persistence on the island.

\section{Discussion}

The present paper provides an overview of mathematical models applied to viral infections in pig populations. With a broad search algorithm, more than 100 publication records meeting the selection criteria were 
identified. The analysis of authors' keywords revealed common scopes: identification of key parameters, evaluation and control of disease spread at herd scales, and modelling spread pattern at large scale to evaluate control measures for regulated diseases.

Swine production is an organized system from within farm, where pigs are housed according to strict predefined husbandry practices (all-in-all-out flow of animals, batches of animals of similar physiological statuses, prophylaxis measures), to commercial trade between production sites. These characteristics lead to different contact structures depending on the scale we're actually interested in, which were already identified as potential weakness points in regards with pathogen spread and persistence [27, 43, 90-92].

Understanding viral infection dynamics in pig herds has been mainly based on observational and experimental studies describing real phenomenons in the field or evaluating assumptions in a controlled way in experimental settings. If several bias and confoundings can be encountered in observational studies, extrapolation of experimental findings to the real life is often challenging. Modelling studies can overcome those drawbacks by putting together all the information coming from different sources in a comprehensive way to represent mechanistically the biological events.

Within-host models are broadly used for human infectious agents, such as human immunodeficiency virus or influenza [93-95], but mathematical modelling of the host-pathogen interactions represents only six records in our selection of modelling studies dealing with pig diseases. Recent studies on SIV and PRSS revealed an impairment of the immune response when challenging piglets having maternally derived antibodies [96, 97]. These impairments were shown to be a key factor favouring the persistence of SIV on farm [59] and an additional source of host heterogeneity in regard to PRRS virus [96]. The kinetics of MDA, and related neutralizing antibodies, could therefore be a key component to understand the vaccination efficacy in the field. Immuno-epidemiological models, combining within-host immunological processes with epidemiological models at population scale, could help optimizing vaccination strategies.

The role of within-herd structure was broadly studied for enzootic agents [43, 56, 98], merging different within- and between-herds infection dynamics frameworks, have been used in the last decade (e.g. NAADSM, InterSpread, DTU-DADS or Be-FAST), mostly to study the spread of regulated diseases. A homogeneous mixing assumption is generally used to represent within-herd infection dynamics coupled with between-herd transmission module [43, 56, 98], but Kinsley et al. showed that the incorporation of accurate population dynamics in herds might shed new light on the actual infectious process [99]. A recent study on HEV spread integrated the compartment structure in pig herds in the SimInf framework [100], a modelling framework originally developed to study VTEC-O157 spread among cattle herds in Sweden [101]. Although more complex; this model accounted for realistic representation of the population demographics, together with the commercial network between production sites based on batch-rearing system. These examples illustrate the need of coupling models across scales. All scales are strongly related and acting on one link in the chain can modify the whole system, with beneficial or detrimental effects.

Halasa et al. [102] compared the outcomes of the Interspread and DTU-DADS frameworks using FMD application for reference disease, showing slight differences of spread patterns and control policies efficiency. Roche et al. [103] performed similar work, comparing modelling frameworks from five countries, namely Australia, New Zealand, USA, UK and the Netherlands. Although the results varied quantitatively, the main conclusions on the effectiveness of control strategy were robust for all models, which clearly help to be confident with their conclusions. In-depth analysis of models' outcomes, based on similar assumptions, could certainly help understanding the impact of the model structures in terms of predictions.

There is a need at different levels and to different aims of modelling based information on viral infectious disease in pigs. The field of application and the representation structure is somehow correlated with the specific target/final user. Hence, models on regulated diseases will be often developed at the between herd scale and will address questions from policy makers in animal health $[68,74,104,105]$, whereas models developed for enzootic diseases are more generally developed on a herd level scale to answer more applied questions on disease control rather relevant for veterinarians and farmers $[43,57,60]$. These models can put together available data from observational and experimental origin and can provide estimates of non measurable facts. A wide range of methodologies have been developed to this aim, either based on representation of field data by a dynamic model or by using a simple model describing the infection dynamics occurring in a controlled experimental setting [29, 35, 42]. These developments have been used for transmission parameter estimation per se, but also to evaluate in experimental conditions the impact of a control measure (often vaccination) on virus transmission [106, 107]. These approaches based on data-designed models need to be distinguished from pure model development of complex structured population in which a pathogen or a combination of pathogens is spreading. This latter strategy has been often 
developed in porcine health management to understand infection dynamics in a comprehensive way by filling the gap of unobserved phenomenon (by observational or experimental studies) $[48,49,60]$. Hence the objective is rarely the pure prediction per se with the exception in specific cases of regulated diseases for the question of the impact of the pathogen in case of introduction in a free territory. Those models are rather used to evaluate assumptions based on in-silico experiments where a tested scenario is evaluated towards a control one. The magnitude of the effect is therefore rather expressed relatively to a baseline than an absolute estimate of the impact, but is extremely efficient in evaluating ex ante the impact of control strategies on an epidemics at different scales and potentially incorporate an economical assessment $[62,78,85]$. The advantage of modelling is the quasi absence of limits in the diversity and numbers of combinations of intervention strategies to be evaluated, which would generally be not possible to assess in real life.

Integrative modelling from within-host to betweenherds virus dynamics is clearly on the way, but model coupling remains challenging $[12,108]$. The rise of computer technology allowed for development of computational tools to address biological issues that could not be unravelled in the past, providing decision-support system to stakeholders. The emergence of artificial intelligence in the field of epidemiology may be a key for unifying multiple paradigms into a single multiscale framework [109]. The understanding of how control measures applied at one scale impact the system at upand downward scales is essential to have a global overview of their efficiencies. The era of big data offers tremendous quantity of information on diseases spread throughout the world, requiring the development of specific methods for their analysis. One may easily understand the cooperative game that is currently played, gathering interdisciplinary research towards the same goal: a better understanding of infectious diseases dynamics for efficient control policies.

\section{Supplementary information}

Supplementary information accompanies this paper at https://doi.org/10. 1186/s40813-020-00160-4.

Additional file 1: Supplementary Material 1. Bibliographic Detail on records meeting the inclusion criteria: 117 articles according to their modelling structure (white: Within-host models, blue: parameter estimation, yellow: within-host model, orange: between-host model).

Additional file 2: Supplementary Material 2. Top journal list for modelling studies on infectious diseases dynamics in pigs.
Authors' contributions

MA and NR performed the literature review and drafted the manuscript. The authors approved the final manuscript before submission.

Availability of data and materials

Not Applicable.

Ethics approval and consent to participate

Not Applicable.

\section{Consent for publication}

Not Applicable.

\section{Competing interests}

The authors declare that they have no competing interests.

Received: 26 February 2020 Accepted: 25 June 2020

Published online: 20 August 2020

\section{References}

1. Lerner $\mathrm{H}$, Berg $\mathrm{C}$. The concept of health in one health and some practical implications for research and education: what is one health? Infect Ecol Epidemiol. 2015:5:25300

2. Keeling MJ, Rohani P. Modeling infectious diseases: in humans and animals: Princeton University press; 2008.

3. Basta S, Gerber H, Schaub A, Summerfield A, McCullough KC. Cellular processes essential for African swine fever virus to infect and replicate in primary macrophages. Vet Microbiol. 2010;140(1-2):9-17.

4. Karalyan Z, Zakaryan H, Sargsyan K, Voskanyan H, Arzumanyan H, Avagyan $\mathrm{H}$, et al. Interferon status and white blood cells during infection with African swine fever virus in vivo. Vet Immunol Immunopathol. 2012;145(1-2):551-5.

5. Murtaugh MP, Xiao Z, Zuckermann F. Immunological responses of swine to porcine reproductive and respiratory syndrome virus infection. Viral Immunol. 2002;15(4):533-47.

6. Fablet C, Simon G, Dorenlor V, Eono F, Eveno E, Gorin S, et al. Different herd level factors associated with $\mathrm{H} 1 \mathrm{~N} 1$ or $\mathrm{H} 1 \mathrm{~N} 2$ influenza virus infections in fattening pigs. Prev Vet Med. 2013;112(3-4):257-65.

7. Maes D, Deluyker H, Verdonck M, Castryck F, Miry C, Vrijens B, et al. Herd factors associated with the seroprevalences of four major respiratory pathogens in slaughter pigs from farrow-to-finish pig herds. Vet Rec. 2000; 31(3):313-27.

8. Rose N, Lunazzi A, Dorenlor V, Merbah T, Eono F, Eloit M, et al. High prevalence of hepatitis $E$ virus in French domestic pigs. Comp Immunol Microbiol Infect Dis. 2011;34(5):419-27.

9. Keeling MJ, Rohani P. Modeling infectious disease in Humals and animals; 2008.

10. Grassly NC, Fraser C. Mathematical models of infectious disease transmission. Nat Rev Microbiol. 2008;6(6):477-87.

11. Hens N, Shkedy Z, Aerts M, Faes C, Van Damme P, Beutels P. Modeling infectious disease parameters based on serological and social contact data a modern statistical perspective. New York: Springer New York : Imprint: Springer; 2012.

12. Gog JR, Pellis L, Wood JL, McLean AR, Arinaminpathy N, Lloyd-Smith JO. Seven challenges in modeling pathogen dynamics within-host and across scales. Epidemics. 2015;10:45-8.

13. VanderWaal K, Deen J. Global trends in infectious diseases of swine. Proc Natl Acad Sci U S A. 2018;115(45):11495-500.

14. Mason-D'Croz D, Bogard JR, Herrero M, Robinson S, Sulser TB, Wiebe K, et al. Modelling the global economic consequences of a major African swine fever outbreak in China. Nature Food. 2020;1(4):221-8.

15. FAO. ASF situation in Asia update. Updated: 05/03/2020. Available from: http://www.fao.org/ag/againfo/programmes/en/empres/ASF/situation_ update.html. Accessed: 14 May 2020.

16. Aria M, Cuccurullo C. Bibliometrix: an R-tool for comprehensive science mapping analysis. J Informet. 2017;11(4):959-75.

17. De Jong MC, Kimman TG. Experimental quantification of vaccine-induced reduction in virus transmission. Vaccine. 1994;12(8):761-6.

18. Miller GY, Forster DL, Tsai J, Bech-Nielsen S. Predicting the number of herds infected with pseudorabies virus in the United States. Am J Vet Res. 1994; 55(5):628-35. 
19. Nielen M, Jalvingh AW, Meuwissen MP, Horst SH, Dijkhuizen AA. Spatial and stochastic simulation to evaluate the impact of events and control measures on the 1997-1998 classical swine fever epidemic in the Netherlands. II. Comparison of control strategies. Prev Vet Med. 1999:42(34):297-317.

20. Stegeman A, Elbers AR, Smak J, de Jong MC. Quantification of the transmission of classical swine fever virus between herds during the 19971998 epidemic in the Netherlands. Prev Vet Med. 1999;42(3-4):219-34.

21. Ivorra B, Martínez-López B, Sánchez-Vizcaíno JM, Ramos ÁM. Mathematical formulation and validation of the be-FAST model for classical swine fever virus spread between and within farms. Ann Oper Res. 2014;219(1):25-47.

22. Howey R, Quan M, Savill NJ, Matthews L, Alexandersen S, Woolhouse M. Effect of the initial dose of foot-and-mouth disease virus on the early viral dynamics within pigs. J R Soc Interface. 2009;6(39):835-47.

23. Doeschl-Wilson A, Galina-Pantoja L. Using mathematical models to gain insight into host-pathogen interaction in mammals: porcine reproductive and respiratory syndrome. In: Host-pathogen interactions: genetics, immunology and physiology: Nova Science Publishers, Inc.; 2010. p. 109-32.

24. Go N, Bidot C, Belloc C, Touzeau S. Integrative model of the immune response to a pulmonary macrophage infection: what determines the infection duration? PLoS One. 2014;9(9):e107818.

25. Go N, Belloc C, Bidot C, Touzeau S. Why, when and how should exposure be considered at the within-host scale? A modelling contribution to PRRSV infection. Math Med Biol. 2019;36(2):179-206.

26. Go N, Touzeau S, Islam Z, Belloc C, Doeschl-Wilson A. How to prevent viremia rebound? Evidence from a PRRSv data-supported model of immune response. BMC Syst Biol. 2019;13(1):15.

27. Cador C, Andraud M, Rose N. Contribution of modelling in the study of transmission dynamics of virus in metapopulations: application to swine influenza a viruses in pig herds. Virologie. 2017;21(4):173-87.

28. Andraud M, Grasland B, Durand B, Cariolet R, Jestin A, Madec F, et al. Modelling the time-dependent transmission rate for porcine circovirus type 2 (PCV2) in pigs using data from serial transmission experiments. J R Soc Interface. 2009;6(30):39-50.

29. Andraud M, Dumarest M, Cariolet R, Aylaj B, Barnaud E, Eono F, et al. Direct contact and environmental contaminations are responsible for HEV transmission in pigs. Vet Res. 2013;44:102.

30. Bouwknegt M, Frankena K, Rutjes SA, Wellenberg GJ, de Roda Husman AM, van der Poel WH, et al. Estimation of hepatitis E virus transmission among pigs due to contact-exposure. Vet Res. 2008;39(5):40.

31. Weesendorp E, Backer J, Stegeman A, Loeffen W. Effect of strain and inoculation dose of classical swine fever virus on within-pen transmission. Vet Res. 2009;40(6):59.

32. Bouma A, De Jong MC, Kimman TG. Transmission of two pseudorabies virus strains that differ in virulence and virus excretion in groups of vaccinated pigs. Am J Vet Res. 1996;57(1):43-7.

33. Bouma A, de Jong MCM, Kimman TG. Transmission of pseudorabies virus within pig populations is independent of the size of the population. Prev Vet Med. 1995;23(3-4):163-72.

34. Eblé P, de Koeijer A, Bouma A, Stegeman A, Dekker A. Quantification of within- and between-pen transmission of foot-and-mouth disease virus in pigs. Vet Res. 2006;37(5):647-54.

35. Guinat C, Gubbins S, Vergne T, Gonzales JL, Dixon L, Pfeiffer DU. Experimental pig-to-pig transmission dynamics for African swine fever virus, Georgia 2007/1 strain. Epidemiol Infect. 2016;144(1):25-34.

36. Cador C, Herve S, Andraud M, Gorin S, Paboeuf F, Barbier N, et al. Maternally-derived antibodies do not prevent transmission of swine influenza a virus between pigs. Vet Res. 2016;47(1):86.

37. Backer JA, Berto A, McCreary C, Martelli F, van der Poel WH. Transmission dynamics of hepatitis $E$ virus in pigs: estimation from field data and effect of vaccination. Epidemics. 2012;4(2):86-92

38. Hu B, Gonzales JL, Gubbins S. Bayesian inference of epidemiological parameters from transmission experiments. Sci Rep. 2017;7(1):16774.

39. Korennoy Fl, Gulenkin VM, Gogin AE, Vergne T, Karaulov AK. Estimating the basic reproductive number for African swine fever using the Ukrainian historical epidemic of 1977. Transbound Emerg Dis. 2017;64(6):1858-66.

40. Andraud M, Casas M, Pavio N, Rose N. Early-life hepatitis e infection in pigs: the importance of maternally-derived antibodies. PLoS One. 2014;9(8): e105527.

41. Tancredi A. Approximate Bayesian inference for discretely observed continuous-time multi-state models. Biometrics. 2019;75(3):966-77.
42. Guinat C, Porphyre T, Gogin A, Dixon L, Pfeiffer DU, Gubbins S. Inferring within-herd transmission parameters for African swine fever virus using mortality data from outbreaks in the Russian Federation. Transbound Emerg Dis. 2018;65(2):e264-e71.

43. Andraud M, Rose N, Grasland B, Pierre JS, Jestin A, Madec F. Influence of husbandry and control measures on porcine circovirus type 2 (PCV-2) dynamics within a farrow-to-finish pig farm: a modelling approach. Prev Vet Med. 2009;92(1-2):38-51.

44. Barongo MB, Bishop RP, Fevre EM, Knobel DL, Ssematimba A. A mathematical model that simulates control options for African swine fever virus (ASFV). PLoS One. 2016;11(7):e0158658.

45. Stark KD, Pfeiffer DU, Morris RS. Within-farm spread of classical swine fever virus--a blueprint for a stochastic simulation model. Vet Q. 2000;22(1):36-43.

46. Arruda AG, Friendship R, Carpenter J, Greer A, Poljak Z. Evaluation of control strategies for porcine reproductive and respiratory syndrome (PRRS) in swine breeding herds using a discrete event agent-based model. PLoS One. 2016;11(11):e0166596.

47. Backer JA, Brouwer $H$, van Schaik $G$, van Roermund HJ. Using mortality data for early detection of classical swine fever in the Netherlands. Prev Vet Med. 2011;99(1):38-47.

48. Jeong J, Aly SS, Cano JP, Polson D, Kass PH, Perez AM. Stochastic model of porcine reproductive and respiratory syndrome virus control strategies on a swine farm in the United States. Am J Vet Res. 2014;75(3):260-7.

49. White LA, Torremorell M, Craft ME. Influenza a virus in swine breeding herds: combination of vaccination and biosecurity practices can reduce likelihood of endemic piglet reservoir. Prev Vet Med. 2017;138:55-69.

50. Diallo AOI, Chevalier V, Cappelle J, Duong V, Fontenille D, Duboz R. How much does direct transmission between pigs contribute to Japanese encephalitis virus circulation? A modelling approach in Cambodia. PLoS One. 2018;13(8):e0201209.

51. Hone J. A mathematical model of detection and dynamics of porcine transmissible gastroenteritis. Epidemiol Infect. 1994;113(1):187-97.

52. Bitsouni V, Lycett S, Opriessnig T, Doeschl-Wilson A. Predicting vaccine effectiveness in livestock populations: a theoretical framework applied to PRRS virus infections in pigs. PLoS One. 2019;14(8):e0220738.

53. Phoo-ngurn P, Kiataramkul C, Chamchod F. Modeling the spread of porcine reproductive and respiratory syndrome virus (PRRSV) in a swine population: transmission dynamics, immunity information, and optimal control strategies. Adv Difference Equations. 2019;2019(1):432.

54. Etbaigha F, RW A, Poljak Z. An SEIR model of influenza a virus infection and reinfection within a farrow-to-finish swine farm. PLoS One. 2018;13(9): e0202493.

55. Murai K, Moriguchi S, Hayama Y, Kobayashi S, Miyazaki A, Tsutsui T, et al. Mathematical modeling of porcine epidemic diarrhea virus dynamics within a farrow-to-finish swine farm to investigate the effects of control measures. Prev Vet Med. 2018;149:115-24.

56. Reynolds JJ, Torremorell M, Craft ME. Mathematical modeling of influenza a virus dynamics within swine farms and the effects of vaccination. PLoS One. 2014;9(8):e106177.

57. Pitzer VE, Aguas R, Riley S, Loeffen WL, Wood JL, Grenfell BT. High turnover drives prolonged persistence of influenza in managed pig herds. J R Soc Interface. 2016;13:20160138.

58. Cador C, Andraud M, Willem L, Rose N. Control of endemic swine flu persistence in farrow-to-finish pig farms: a stochastic metapopulation modeling assessment. Vet Res. 2017:48(1):58.

59. Cador C, Rose N, Willem L, Andraud M. Maternally derived immunity extends swine influenza a virus persistence within farrow-to-finish pig farms: insights from a stochastic event-driven Metapopulation model. PLoS One. 2016;11(9):e0163672.

60. Salines M, Rose N, Andraud M. Tackling hepatitis E virus spread and persistence on farrow-to-finish pig farms: insights from a stochastic individual-based multi-pathogen model. Epidemics. 2019;30:100369.

61. Costard S, Zagmutt FJ, Porphyre T, Pfeiffer DU. Small-scale pig farmers' behavior, silent release of African swine fever virus and consequences for disease spread. Sci Rep. 2015;5:17074.

62. Buijtels J, Huirne R, Dijkhuizen A, de Jong M, van Nes A. Computer simulation to support policy making in the control of pseudorabies. Vet Microbiol. 1997;55(1-4):181-5.

63. Van Nes A, De Jong MC, Buijtels JA, Verheijden JH. Implications derived from a mathematical model for eradication of pseudorabies virus. Prev Vet Med. 1998;33(1-4):39-58. 
64. Ferguson NM, Donnelly CA, Anderson RM. The foot-and-mouth epidemic in Great Britain: pattern of spread and impact of interventions. Science (New York, NY). 2001;292(5519):1155-60.

65. Tildesley MJ, Keeling MJ. Modelling foot-and-mouth disease: a comparison between the UK and Denmark. Prev Vet Med. 2008;85(1-2):107-24.

66. Klinkenberg $D$, Nielen $M$, Mourits $M C$, de Jong MC. The effectiveness of classical swine fever surveillance programmes in the Netherlands. Prev Vet Med. 2005;67(1):19-37.

67. Sorensen JH, Mackay DK, Jensen CO, Donaldson Al. An integrated model to predict the atmospheric spread of foot-and-mouth disease virus. Epidemiol Infect. 2000;124(3):577-90.

68. Martínez-López B, Perez AM, Sánchez-Vizcaíno JM. A simulation model for the potential spread of foot-and-mouth disease in the castile and Leon region of Spain. Prev Vet Med. 2010;96(1-2):19-29.

69. Hayama Y, Yamamoto T, Kobayashi S, Muroga N, Tsutsui T. Mathematical model of the 2010 foot-and-mouth disease epidemic in Japan and evaluation of control measures. Prev Vet Med. 2013:112(3-4):183-93.

70. Bates TW, Thurmond MC, Carpenter TE. Results of epidemic simulation modeling to evaluate strategies to control an outbreak of foot-and-mouth disease. Am J Vet Res. 2003;64(2):205-10.

71. Backer JA, Hagenaars TJ, Nodelijk G, van Roermund HJ. Vaccination against foot-and-mouth disease I: epidemiological consequences. Prev Vet Med. 2012;107(1-2):27-40

72. Martínez-López B, Ivorra B, Ramos AM, Sánchez-Vizcaíno JM. A novel spatial and stochastic model to evaluate the within- and between-farm transmission of classical swine fever virus. I. General concepts and description of the model. Vet Microbiol. 2011;147(3-4):300-9.

73. Klinkenberg D, Everts-van der Wind A, Graat EA, de Jong MC. Quantification of the effect of control strategies on classical swine fever epidemics. Math Biosci. 2003;186(2):145-73.

74. Dürr S, Zu Dohna H, Di Labio E, Carpenter TE, Doherr MG. Evaluation of control and surveillance strategies for classical swine fever using a simulation model. Prev Vet Med. 2013;108(1):73-84.

75. Backer JA, Hagenaars TJ, van Roermund HJ, de Jong MC. Modelling the effectiveness and risks of vaccination strategies to control classical swine fever epidemics. J R Soc Interface. 2009:6(39):849-61.

76. Backer JA, Vrancken R, Neyts J, Goris N. The potential of antiviral agents to control classical swine fever: a modelling study. Antiviral Res. 2013;99(3): 245-50.

77. Stevenson MA, Sanson RL, Stern MW, O'Leary BD, Sujau M, Moles-Benfell N, et al. InterSpread plus: a spatial and stochastic simulation model of disease in animal populations. Prev Vet Med. 2013;109(1-2):10-24.

78. Boklund A, Toft N, Alban L, Uttenthal A. Comparing the epidemiological and economic effects of control strategies against classical swine fever in Denmark. Prev Vet Med. 2009:90(3-4):180-93.

79. Wada M, Stevenson M, Cogger N, Carpenter T. Evaluation of the control strategy for the 2010 foot-and-mouth disease outbreak in Japan using disease simulation. Transbound Emerg Dis. 2017;64(3):978-89.

80. Harvey N, Reeves A, Schoenbaum MA, Zagmutt-Vergara FJ, Dube C, Hill AE, et al. The north American animal disease spread model: a simulation model to assist decision making in evaluating animal disease incursions. Prev Vet Med. 2007;82(3-4):176-97.

81. Dorjee S, Revie CW, Poljak Z, McNab WB, McClure JT, Sanchez J. One-health simulation modelling: assessment of control strategies against the spread of influenza between swine and human populations using NAADSM. Transbound Emerg Dis. 2016;63(2):e229-44.

82. Rose N, Andraud M, Blanchard Y, Grasland B. Modelling the spread of the porcine epidemic diarrhea virus in case of introduction into a densely populated area, with no prior immunity. Epidemiologie et Sante Animale. 2015:67:27-38

83. Thakur KK, Revie CW, Hurnik D, Poljak Z, Sanchez J. Simulation of betweenfarm transmission of porcine reproductive and respiratory syndrome virus in Ontario, Canada using the north American animal disease spread model. Prev Vet Med. 2015;118(4):413-26.

84. Bates TW, Thurmond MC, Carpenter TE. Description of an epidemic simulation model for use in evaluating strategies to control an outbreak of foot-and-mouth disease. Am J Vet Res. 2003;64(2):195-204.

85. Halasa T, Bøtner A, Mortensen S, Christensen H, Toft N, Boklund A Simulating the epidemiological and economic effects of an African swine fever epidemic in industrialized swine populations. Vet Microbiol. 2016;193: $7-16$.
86. Martínez-López B, Ivorra B, Ramos AM, Fernández-Carrión E, Alexandrov T, Sánchez-Vizcaíno JM. Evaluation of the risk of classical swine fever (CSF) spread from backyard pigs to other domestic pigs by using the spatial stochastic disease spread model be-FAST: the example of Bulgaria. Vet Microbiol. 2013;165(1-2):79-85.

87. Mur L, Sánchez-Vizcaíno JM, Fernández-Carrión E, Jurado C, Rolesu S, Feliziani F, et al. Understanding African swine fever infection dynamics in Sardinia using a spatially explicit transmission model in domestic pig farms. Transbound Emerg Dis. 2018;65(1):123-34.

88. Halasa T, Botner A, Mortensen S, Christensen H, Toft N, Boklund A. Control of African swine fever epidemics in industrialized swine populations. Vet Microbiol. 2016;197:142-50.

89. Halasa T, Botner A, Mortensen S, Christensen H, Wulff SB, Boklund A. Modeling the effects of duration and size of the control zones on the consequences of a hypothetical African swine fever epidemic in Denmark. Frontiers Veterinary Sci. 2018;5:49.

90. Kukielka EA, Martínez-López B, Beltrán-Alcrudo D. Modeling the live-pig trade network in Georgia: implications for disease prevention and control. PLoS One. 2017;12(6):e0178904.

91. Salines M, Andraud M, Rose N. Combining network analysis with epidemiological data to inform risk-based surveillance: application to hepatitis E virus (HEV) in pigs. Prev Vet Med. 2018;149:125-31.

92. Maurice H, Thulke HH, Schmid JS, Stegeman A, Nielen M. The impact of compartmentalised housing on direct encephalomyocarditis virus (EMCV) transmission among pigs; insight from a model. Prev Vet Med. 2016;127:105-12.

93. Canini L, Perelson AS. Viral kinetic modeling: state of the art. J Pharmacokinet Pharmacodyn. 2014;41(5):431-43.

94. Clapham HE, Tricou V, Van Vinh CN, Simmons CP, Ferguson NM. Within-host viral dynamics of dengue serotype 1 infection. J R Soc Interface. 2014;11(96): 20140094.

95. Perelson AS, Neumann AU, Markowitz M, Leonard JM, Ho DD. HIV-1 dynamics in vivo: Virion clearance rate, infected cell life-span, and viral generation time. Science. 1996;271(5255):1582-6.

96. Fablet C, Renson P, Eono F, Mahe S, Eveno E, Le Dimna M, et al. Maternallyderived antibodies (MDAs) impair piglets' humoral and cellular immune responses to vaccination against porcine reproductive and respiratory syndrome (PRRS). Vet Microbiol. 2016;192:175-80.

97. Renson P, Fablet C, Andraud M, Normand V, Lebret A, Paboeuf F, et al. Maternally-derived neutralizing antibodies reduce vaccine efficacy against porcine reproductive and respiratory syndrome virus infection. Vaccine. 2019;37(31):4318-24

98. Evans CM, Medley GF, Creasey SJ, Green LE. A stochastic mathematical model of the within-herd transmission dynamics of porcine reproductive and respiratory syndrome virus (PRRSV): fade-out and persistence. Prev Vet Med. 2010;93(4):248-57.

99. Kinsley AC, VanderWaal K, Craft ME, Morrison RB, Perez AM. Managing complexity: simplifying assumptions of foot-and-mouth disease models for swine. Transbound Emerg Dis. 2018;65(5):1307-17.

100. Salines M, Andraud M, Rose N, Widgren S. A between-herd datadriven stochastic model to explore the spatio-temporal spread of hepatitis $\mathrm{E}$ virus in the French pig production network. PLoS One. 2020;15(7):e0230257.

101. Widgren S, Engblom S, Bauer P, Frossling J, Emanuelson U, Lindberg A. Data-driven network modelling of disease transmission using complete population movement data: spread of VTEC 0157 in Swedish cattle. Vet Res. 2016;47(1):81

102. Halasa T, Boklund A, Stockmarr A, Enoe C, Christiansen LE. A comparison between two simulation models for spread of foot-and-mouth disease. PLoS One. 2014;9(3):e92521.

103. Roche SE, Garner MG, Sanson RL, Cook C, Birch C, Backer JA, et al. Evaluating vaccination strategies to control foot-and-mouth disease: a model comparison study. Epidemiol Infect. 2015;143(6):1256-75.

104. Andraud M, Halasa T, Boklund A, Rose N. Threat to the French swine industry of African swine fever: surveillance, spread, and control perspectives. Frontiers Veterinary Sci. 2019;6:248.

105. Ward MP, Highfield LD, Vongseng P, Graeme GM. Simulation of foot-andmouth disease spread within an integrated livestock system in Texas, USA Prev Vet Med. 2009;88(4):286-97.

106. Rose N, Andraud M, Bigault L, Jestin A, Grasland B. A commercial PCV2abased vaccine significantly reduces $P C V 2 b$ transmission in experimental conditions. Vaccine. 2016;34(33):3738-45. 
107. Rose N, Renson P, Andraud M, Paboeuf F, Le Potier MF, Bourry O. Porcine reproductive and respiratory syndrome virus (PRRSv) modified-live vaccine reduces virus transmission in experimental conditions. Vaccine. 2015;33(21): 2493-9.

108. Ezanno P, Andraud M, Beaunée G, Hoch T, Krebs S, Rault A, et al. How mechanistic modelling supports decision making for the control of enzootic infectious diseases. Epidemics. 2020;32. In Press.

109. Picault S, Huang Y-L, Sicard V, Arnoux S, Beaunée G, Ezanno P. EMULSION: transparent and flexible multiscale stochastic models in human, animal and plant epidemiology. PLoS Comput Biol. 2019;15(9):e1007342.

\section{Publisher's Note}

Springer Nature remains neutral with regard to jurisdictional claims in published maps and institutional affiliations.

Ready to submit your research? Choose BMC and benefit from:

- fast, convenient online submission

- thorough peer review by experienced researchers in your field

- rapid publication on acceptance

- support for research data, including large and complex data types

- gold Open Access which fosters wider collaboration and increased citations

- maximum visibility for your research: over $100 \mathrm{M}$ website views per year

At BMC, research is always in progress.

Learn more biomedcentral.com/submissions 